\title{
Microstructural Evolution of Blast Furnace Coke During Experimental Heating - The IFORS Approach
}

\author{
Gerd Rantitsch ${ }^{1,2}$, Anrin Bhattacharyya ${ }^{1}$, and Johannes Schenk ${ }^{1}$ \\ ${ }^{1}$ Montanuniversität Leoben, Leoben, Austria \\ ${ }^{2}$ Montanuniversität Leoben, Lehrstuhl für Geologie und Lagerstättenlehre, Leoben, Austria
}

Received November 7, 2018; accepted January 22, 2019; published online June 12, 2019

\begin{abstract}
Blast furnace coke has been experimentally heated between $850^{\circ} \mathrm{C}$ and $1100^{\circ} \mathrm{C}$ by varying the gas composition and the alkali content of the raw coke. Raman spectroscopy and "Iterative Fitting of Raman Spectra" (IFORS) evaluates the microstructural change of coke during the experiments. The obtained results indicate a significant microstructural variation within a bulk sample. This variation controls significantly the coke quality as estimated from standard experiments $(23.9<\mathrm{CRI}>38.3)$. A bulk sample with a $\mathrm{CRI}$ value $<30$ is composed dominantly of lumps showing a relatively low structural ordering. During experimental heating, the structural ordering of such lumps increases. A bulk sample with a CRI value $>30$ is composed dominantly of lumps showing a relatively high structural ordering. During experimental heating, the structural state of such lumps remains unchanged unless a strong reaction is induced by adding alkaline elements. It is supposed that, under laboratory conditions, thermal and chemical energy, affecting a microstructurally low-ordered coke, first reorganizes the structural state of the individual coke lumps, retarding the onset of the Boudouard reaction.
\end{abstract}

Keywords: Blast furnace coke, Raman spectroscopy, Experiments

Die mikrostrukturelle Entwicklung von Hochofenkoks in einem vertikalen Retortenofen - der IFORS-Ansatz

Zusammenfassung: In einem vertikalen Retortenofen wurde Hochofenkoks zwischen $850^{\circ} \mathrm{C}$ und $1100^{\circ} \mathrm{C}$ mit unterschiedlicher Gas-Zusammensetzung und mit unterschiedlichem Alkaligehalt experimentell untersucht. Die RamanSpektroskopie und der IFORS (,Iterative Fitting of Raman Spectra") - Ansatz bewerten dabei die mikrostrukturelle

\section{G. Rantitsch ( $\bowtie)$}

Montanuniversität Leoben,

Lehrstuhl für Geologie und Lagerstättenlehre,

Peter Tunner Straße 5,

8700 Leoben, Austria

gerd.rantitsch@unileoben.ac.at
Änderung der Koksstruktur während dieser Experimente. Die Ergebnisse zeigen eine signifikante Variation der Mikrostruktur in einer Probe an. Dies beeinflusst die Koksqualität, wie sie durch Standard-Experimente bestimmt wurde $(23.9<\mathrm{CRI}>38.3)$. Eine Gesamtprobe mit $\mathrm{CRI}<30$ besteht vorwiegend aus Körnern mit geringer struktureller Ordnung. Diese verbessert sich durch die Experimente. Eine Gesamtprobe mit CRI >30 besteht vorwiegend aus Körnern mit einer besseren strukturellen Ordnung. Während der Experimente bleibt dieser Zustand unverändert. Eine verbesserte Strukturordnung kann durch den Zusatz von Alkalien erreicht werden. Es wird vermutet, dass unter Laborbedingungen die thermische und chemische Energie zuerst den Ordnungszustand eines Kokskorns verbessert und dadurch den Einsatz der Boudouard-Reaktion verzögert.

Schlüsselwörter: Hochofenkoks, Raman-Spektroskopie, Reaktionsexperimente

\section{Introduction}

Raman spectroscopy evaluates the organization degree of the carbonaceous constituents of coke [1], being a promising material property to optimize the use of this material in the blast furnace (e.g. [2]). Among others, this property is an important factor influencing the Coke Reactivity Index (CRI) and Coke Strength after Reaction (CSR) values, used by steelmakers to maintain their blast furnace coke quality. Former work [1, 3] demonstrates that a spectral parameter may be used in the future to predict confidently the coke quality by applying an effective and non-destructive method. Raman Spectroscopy was applied in experimental studies to examine the transformation of coal to coke [3] and to explore the transformation of coke within the blast furnace [1]. Generally, the aim of many Raman studies is to find specific parameters or parameter combinations to predict a material property, which needs more effort to estimate, or to express a complex process (like graphitization within a furnace) by a simple number. However, all such 


\begin{tabular}{|c|c|c|c|c|c|c|c|}
\hline & \multicolumn{4}{|c|}{ Experimental design ( $N=$ number of experiments) } & & & \\
\hline & & $\mathrm{CO}_{2}$ & $\mathrm{CO}_{2}+\mathrm{N}_{2}$ & $\mathrm{~N}_{2}$ & $\mathrm{CO}_{2}+\mathrm{H}_{2} \mathrm{O}$ & $\mathrm{CO}_{2}+1.5-1.7 \% \mathrm{~K}$ & $\mathrm{CO}_{2}+0.6-2.1 \% \mathrm{Na}$ \\
\hline \multirow[t]{4}{*}{ Temperature } & $850^{\circ} \mathrm{C}$ & 4 & - & - & - & - & - \\
\hline & $900^{\circ} \mathrm{C}$ & 4 & - & - & - & - & - \\
\hline & $1000^{\circ} \mathrm{C}$ & 4 & - & - & - & - & - \\
\hline & $1100^{\circ} \mathrm{C}$ & 9 & 5 & 2 & 6 & 3 & 4 \\
\hline
\end{tabular}

approaches are hampered by the presence of significant methodological error sources [4], preventing the use of the Raman approach as an industrial standard.

The aim of this contribution is therefore to propose the "Iterative Fitting of Raman Spectra-IFORS" approach of [5] as a standardized method to avoid the operator bias during Raman curve-fitting, which has a particular high impact in the estimation of Raman spectral values. For this purpose, experimental data are used. They should help to examine the microstructural evolution of carbonaceous matter during high-temperature heating of metallurgical coke, which is currently not yet completely understood.

\section{Methods}

Nine industrial blast furnace coke samples $(23.9<\mathrm{CRI}>38.3)$ come from Austria, Germany, the Netherlands, and Poland. Their characteristics indicate the typical quality range of coke used in ironmaking. According to ISO18894 [6], the Coke Reactivity Index (CRI) was estimated using the vertical retort furnace aggregate of the Chair of Ferrous Metallurgy, Montanuniversität Leoben. In this test, a bulk sample of $200 \pm 3 \mathrm{~g}$, composed of lumps in a size of 19.0 to $22.4 \mathrm{~mm}$, was treated under standard conditions (treatment at $1100^{\circ} \mathrm{C}$ for $120 \mathrm{~min}$ under a $\mathrm{CO}_{2}$ atmosphere, after preheating in a nitrogen atmosphere). In further experiments, gas composition and reaction temperatures were varied according to Table 1. Some experiments were done by adding alkaline elements to the raw coke [7]. Coke Strength after Reaction (CSR; [6]) was determined by using a twin tumbler system (Model TB 5000 of R.B. Automazione, Genoa, Italy).

Raman spectra were acquired by using a Dilor Raman spectrometer equipped with an Nd-YAG laser $(532.2 \mathrm{~nm})$ as described in [1]. In the numerical analysis of Raman spectra, significant methodological problems arise from labspecific constraints [4]. Therefore, the Raman spectra were evaluated by the IFORS approach of [8], excluding subjectivity in curve-fitting [5]. As a key parameter, the Scaled Total Area, normalized to the Dmax band (D-STA; [5]) is used to characterize the microstructurally state of the coke lumps.

To assess the microstructural within-sample variability, 10 lumps of representative coke samples were examined by analyzing three random spots per lump on the outer lump surface. One lump of a bulk sample was halved. One halve was marked and examined by Raman spectroscopy after undergoing the experiment. The second halve, serving as a reference, was examined in the untreated form [1].
This procedure allows comparing directly the change of the Raman spectrum during the experiments [1].

\section{Results}

The collected Raman spectra (Fig. 1) are similar to spectra observed on $\mathrm{CM}$ enclosed in low-temperature metamorphosed rocks. Hence, they are described here by the D-STA parameter of [9]. Decreasing values reflect the progressive aromaticity of the $\mathrm{CM}$ [9]. It is important to note that the estimated D-STA values describe the coke spectra differently than the natural CM spectra. For a given D-STA value, the Dmax band in coke has a significantly higher intensity than the Dmax band in a corresponding natural CM sample (Fig. 1). However, the corresponding trend shown in Fig. 1, and a downwards shift of the Dmax position with decreasing D-STA values, accompanied by a shift of the Gmax position towards higher values, indicates the progressive evolution of the $\mathrm{CM}$ to a better organized organic material.

In a bulk sample, the D-STA values scatter significantly (Fig. 2). The data suggest a normal distribution, which is disturbed by outliers on both tails.

The experiments intend to attack the coke samples by increasing thermal and chemical energy, simulating the progressive transformation of coke during travelling within the blast furnace. From the estimated reactivity and strength values, the coke reaction is measured. The results demonstrate the progressive reaction from CRI 0.6 to CRI 73.8 with rising temperatures. The CSR values are negatively correlated to the $\mathrm{CRI}$ values.

Experiments at $1100^{\circ} \mathrm{C}$ show that the addition of nitrogen results in a lower reactivity. The opposite is true if $\mathrm{H}_{2} \mathrm{O}$ is added to the combustion gas. As described by [7], the doping of the coke by alkaline elements accelerates the coke reaction significantly. The experimental design enables the direct observation of the change of the D-STA value within a cut through a coke lump. Differences are assessed by the statistically robust Kolmogorov-Smirnov test at the significance level of 0.98 . It is shown that almost all experiments result in a decrease of the estimated D-STA median values. The difference is statistically significant if either the D-STA median exceeds 228-234 or a high amount of energy, resulting in a CRI above 29-36, is applied. Some few experiments with low D-STA starting values show an increase of D-STA during experimental heating. 


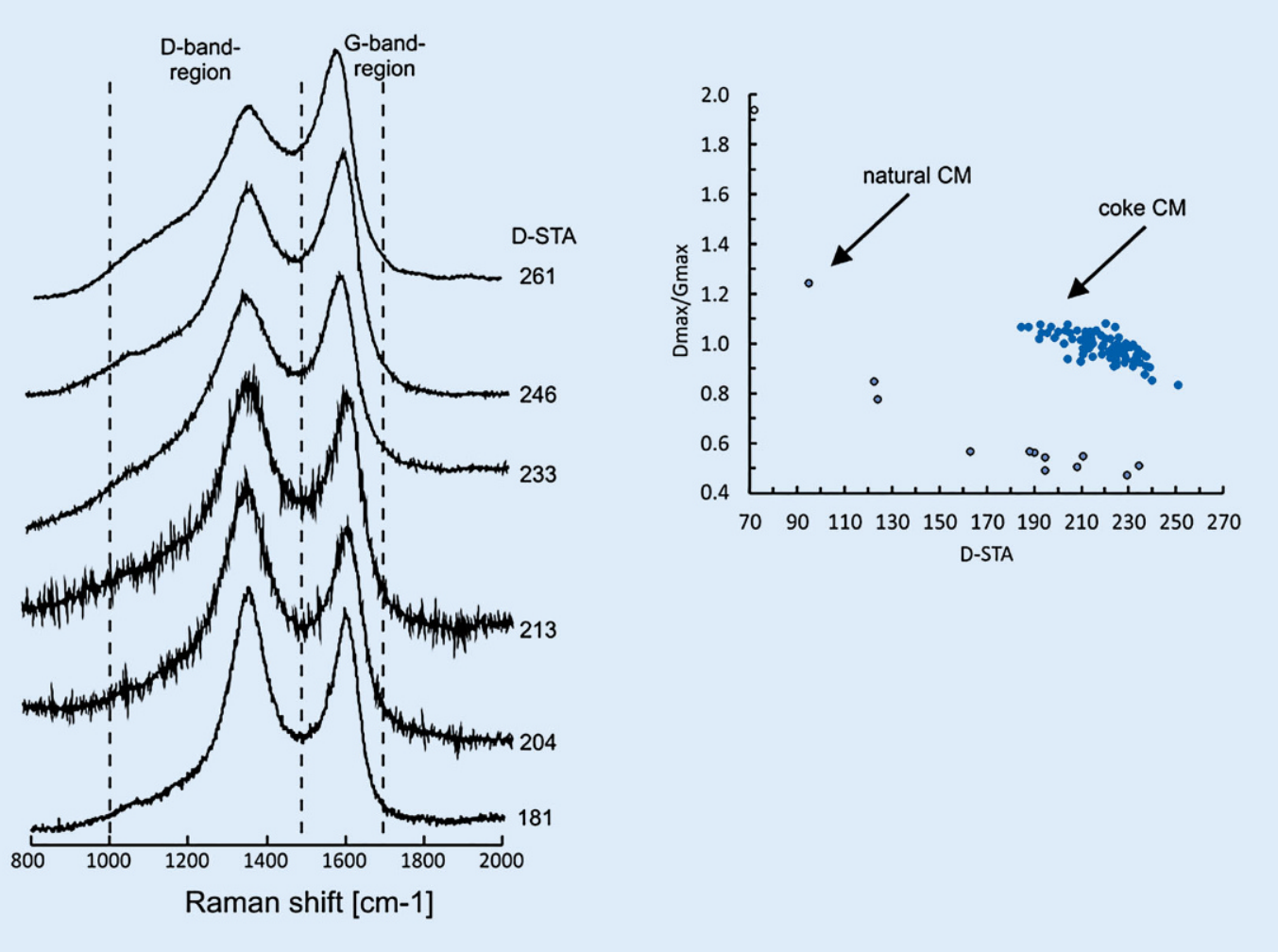

Fig. 1: Representative Raman spectra of coke (left), characterized by the D-STA parameter (lower numbers indicate a better structural organization) of Lünsdorf et al. [5]. The observed Dmax/Gmax peak ratio versus D-STA relation (right) is shown in comparison to data from natural carbonaceous matter [5]

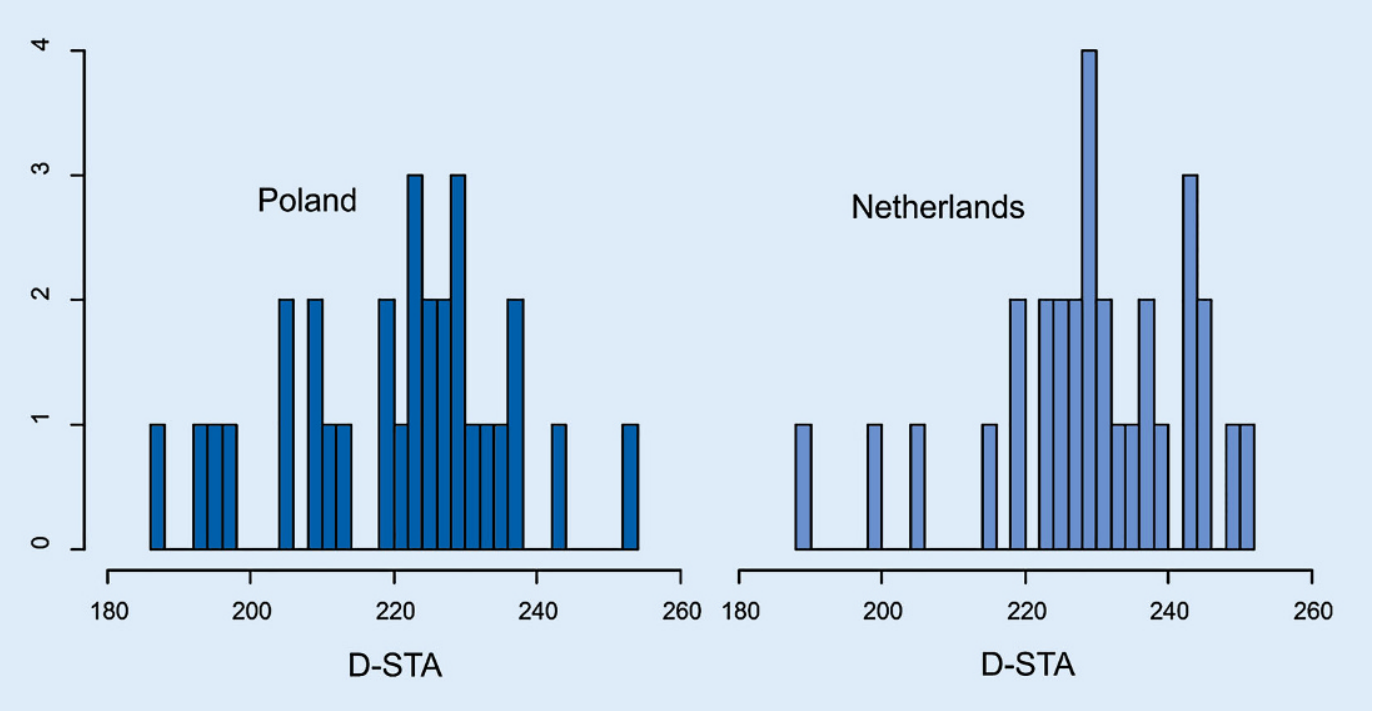

Fig. 2: D-STA [5] variation within two representative coke samples $(n=30)$

\section{Discussion and Conclusions}

According to well-established studies, the D-STA parameter is correlated to the organization state of the organic structural units. The obtained D-STA data of this study demonstrate a high degree of micro-structurally heterogeneity within a coke sample. This is reflected by sim- ilar variation coefficients of the within-lump and withinsample D-STA estimates. Thus, any attempt to explore the microstructural evolution of coke must be performed on individual coke lumps. If a structural parameter (e.g. a XRD-based lattice parameter) is estimated from a bulk sample, any conclusion is weakened by the inherent structural within-sample variability. 
The data of this study show that high-temperature heating up to $1100^{\circ} \mathrm{C}$ improves the microstructural order of coke. The reaction progress depends on the microstructural starting conditions. Up to $1100^{\circ}$ a relatively well-ordered structure shows no change or a decrease of the organization degree. A contribution of alkaline elements is needed to induce a change of the microstructure. In contrast, as observed in experiments at $850^{\circ} \mathrm{C}$, the organization degree of a relatively low-ordered structure is improved even at lower temperatures. According to former work [1], the latter process characterizes low-reactive coke samples. In a preliminary model, a two-step process explains this observation. In low-ordered, low-reactive coke, first the aromaticity of the carbonaceous matter increases without major progress of the Boudouard reaction. After reaching a distinct degree of organization, coke reacts intensely.

Acknowledgements. Support by the K1-MET project "Competence Centre for Excellent Technologies in Advanced Metallurgical and Environmental Process Development" and the Bridge project "Forecast of Coke Quality under Blast Furnace Condition by Holistic Characterization" of the Austrian Research Promotion Agency (FFG) is gratefully acknowledged.

Funding. Open access funding provided by Montanuniversität Leoben.

Open Access This article is distributed under the terms of the Creative Commons Attribution 4.0 International License (http://creativecommons. org/licenses/by/4.0/), which permits unrestricted use, distribution, and reproduction in any medium, provided you give appropriate credit to the original author(s) and the source, provide a link to the Creative Commons license, and indicate if changes were made.

\section{References}

1. Rantitsch, G.; Bhattacharyya, A.; Schenk, J.; Lünsdorf, N. K.: Assessing the quality of metallurgical coke by Raman spectroscopy. International Journal of Coal Geology, 130 (2014), pp 1-7

2. Li, K.; Khanna, R.; Zhang, J.; Liu, Z.; Sahajwalla V.; Yang T.; and D. Kong, D.: The evolution of structural order, microstructure and mineral matter of metallurgical coke in a blast furnace: A review, Fuel, 133 (2014), pp 194-215

3. Morga, R.; Jelonek, I.; Kruszewska, K.; Szulik, W.: Relationships between quality of coals, resulting cokes, and micro-Raman spectral characteristics of these cokes, International Journal of Coal Geology, 144-145 (2015), pp 130-137

4. Lünsdorf, N. K.; Dunkl, I.; Schmidt, B. C.; Rantitsch, G.; von Eynatten, H.: Towards a higher comparability of geothermometric data obtained by Raman spectroscopy of carbonaceous material. Part I: Evaluation of biasing factors, Geostandards and Geoanalytical Research, 38 (2014), pp 73-94

5. Lünsdorf, N. K.; Dunkl, I.; Schmidt, B. C.; Rantitsch, G.; von Eynatten, H.: Towards a higher comparability of geothermometric data obtained by Raman spectroscopy of carbonaceous material. Part 2: A revised geothermometer, Geostandards and Geoanalytical Research, 41 (2017), pp 593-612

6. ISO 18894 (2006). Coke-Determination of coke reactivity index (CRI) and coke strength after reaction (CSR), 2006

7. Bhattacharyya, A.; Schenk, J.; Rantitsch, G.; Thaler, C.; Stocker, H.: Effect of alkaline elements on the reactivity, strength and structural properties of blast furnace cokes, Metalurgija, 54 (2015), pp 503-506

8. Lünsdorf, N. K.; Lünsdorf, J. O.: Evaluating Raman spectra of carbonaceous matter by automated, iterative curve-fitting, International Journal of Coal Geology, 160-161 (2016), pp 51-62

9. Lünsdorf, N. K.: Raman spectroscopy of dispersed vitrinite-Methodical aspects and correlation with reflectance, International Journal of Coal Geology, 153 (2016), pp 75-86

Publisher's Note. Springer Nature remains neutral with regard to jurisdictional claims in published maps and institutional affiliations. 